\title{
Finite Element Simulation of Grinding Performance and Grain Shapes in Grinding Superalloy-Inconel
}

\author{
Lianjie $\mathrm{Ma}^{1}$, Aibing $\mathrm{Yu}^{2}$, Jia Wang ${ }^{1}$, Chen $\mathrm{Li}^{1}$, Fengwen Wang ${ }^{1}$ \\ 1. School of Control Engineering, Northeastern University at Qinhuangdao, Qinhuangdao 066004, China \\ ${ }^{2}$ Faculty of Mechanical Engineering and Mechanics, Ningbo University, Ningbo 315211, China
}

\begin{abstract}
The influence of different grain shape on the grinding characteristics was simulated based on DEFORM in grinding superalloy-incone. The grinding force, heat flux and maximum grinding temperature were studied in different grain shapes. Results indicated that increasing of the edges number of the multi-pyramid, the resultant force $F$, normal grinding force $\mathrm{Fz}$ and tangential grinding force $\mathrm{Fy}$ were uptrend, but the grinding force in feeding direction was downtrend. Heat flux of grain was small in triangular pyramid, rectangular pyramid, pentagonal pyramid, hexagonal pyramid. The temperature area of cone and multi-pyramids was larger than others. The influence of the grain number of edges, the maximum grinding temperature appeared uptrend overall.
\end{abstract}

Keywords-grain shape; grinding force; grinding temperature; heat flux; superalloy-inconel718.

\section{INTRODUCTION}

Grinding is an important technology for precision and ultraprecision machining in modern manufacture. Grain shape was important for the efficiency and precision in grinding. $\mathrm{Su}$ simulated the cutting process of irregular polyhedral grains by LS-DYNA[1]. Fang simulated the grinding process of ball grain[2]. The cutting force, temperature distribution and chip flow could accurately simulated by DEFOEM in the metal cutting process[3]. By Deform-3D, 7075 aluminum alloy was simulated with milling module, and the influence regularity of cutting speed, cutting depth, feed rate on cutting force was analyzed[4]. In this paper, the simulation object was grinding Superalloy-Inconel718. The grinding force and the grinding heat were compared and analyzed under different grain shape.

\section{SiMULATION OF FinITE ELEMENT}

The parameter of CBN wheel: density is $3.46 \mathrm{~g} / \mathrm{cm}^{3}$, Young's modulus is $70.6 \mathrm{GPa}$, specific heat capacity is 670 $\mathrm{J} /(\mathrm{kg} \cdot \mathrm{K})$, thermal conductivity is $1.47 \times 10^{-5} / \mathrm{K}$, grain semi cone angle is $120^{\circ}$. Superalloy-Inconel 718 was selected. The assembling of workpiece and grains was shown in Fig.1. The environment temperature was $20^{\circ} \mathrm{C}$, grinding speed was $50 \mathrm{~m} / \mathrm{s}$, feed speed was $0.3 \mathrm{~mm} / \mathrm{s}$, grinding depth was $30 \mu \mathrm{m}$. The ten kinds of grain shapes were designed, the edge number of multi-pyramid was 3 to 10 , and the other was cone. The grinding force, grinding temperature and heat flux were studied under different grain shape.

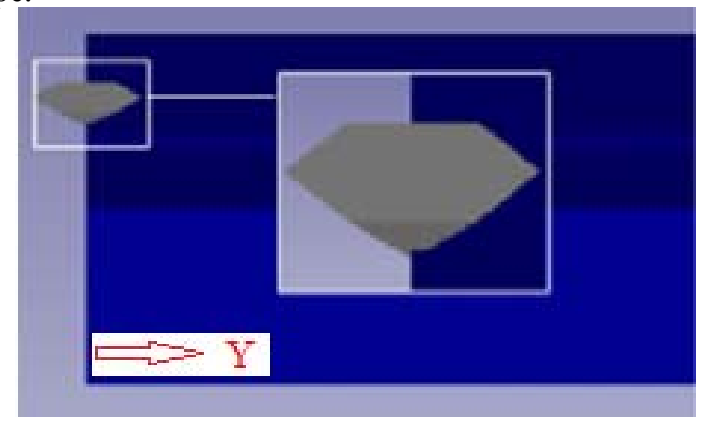

Figure 1. The simulation result of single grain in plane grinding

The changing process of grinding force was shown in Fig.2. The normal grinding force $F_{z}$ was larger than tangential grinding force $F_{y}$, and the grinding force $F_{x}$ in feed direction was near zero.

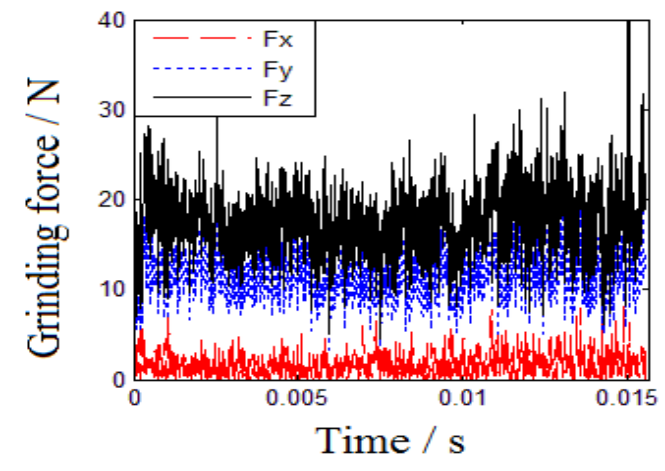

Figure 2. The changing process of grinding force

\section{RESULTS AND DISCUSSIONS}

A. Influence of grain shape on grinding force

Increasing of the number of edges, the resultant force $F$, normal grinding force $F_{z}$ and tangential grinding force $F_{y}$ were uptrend, however, the grinding force $F_{X}$ in feed direction was downtrend(refer in Fig.3). 


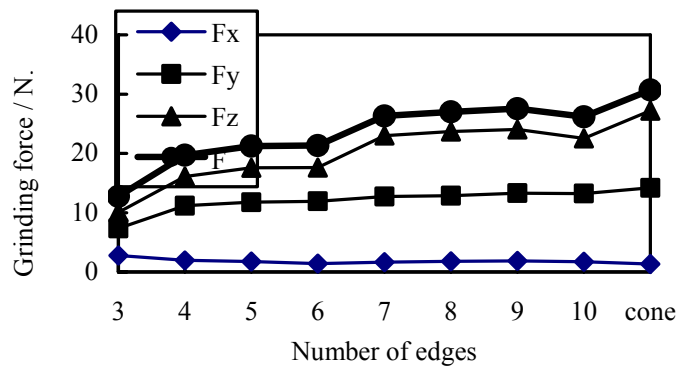

Figure 3. Grinding force under different of grain shape.

Refer in Fig.4, it was directly related between grinding force and the energy of grinding chip formation. When the grinding depth was constant, increasing of $\theta$, the contact area increased. $\theta$ was the angle between workpiece-grain-contact surface and cutting-edge-form surface. The contact area of triangular pyramid was minimum, and contact area of cone was maximum. When the grinding parameters and grain moving distance were unchanging, the grain obtained energy was the same. Because of different contact area, for triangular pyramid chip separation volume and energy required were minimum, grinding force was maximum. Similarly, grinding force of cone was maximum.

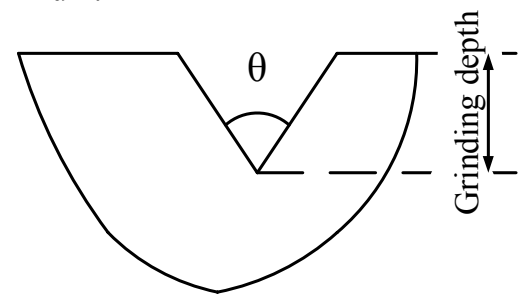

Figure 4. Schematic diagram of grinding depth

\section{B. Influence of grain shape on heat flux}

The heat flux was significant different with different grain shape (Refer in Fig.5). The heat flux was less for triangular pyramid, rectangular pyramid, pentagonal pyramid and hexagonal pyramid. And the heat flux was high for others of grain shapes.

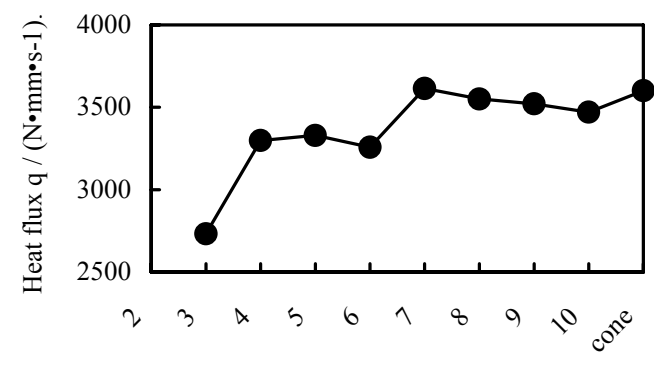

Number of edges

Figure 5. The heat flux for different grain shape

\section{Influence of grain shape on grinding temperature}

The change process of grinding temperature was shown in Fig.6a. The grinding temperature diffused from the main cutting edge around. The highest temperature appeared contact area between grain and workpiece, but did not appear at the tip of grain (Refer in Fig.6b and Fig.6c).

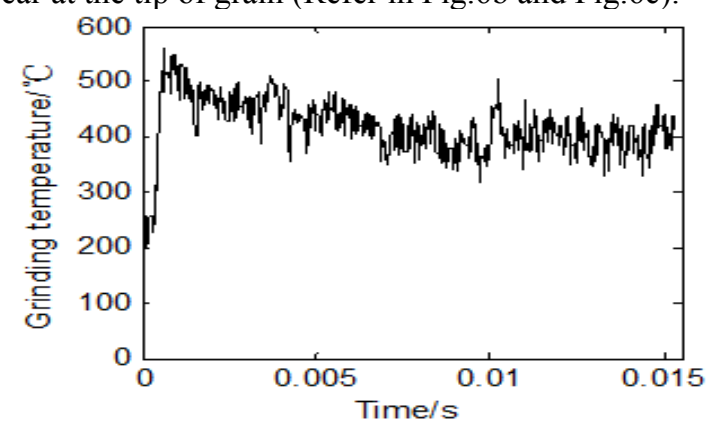

(a) The change process of grinding temperature

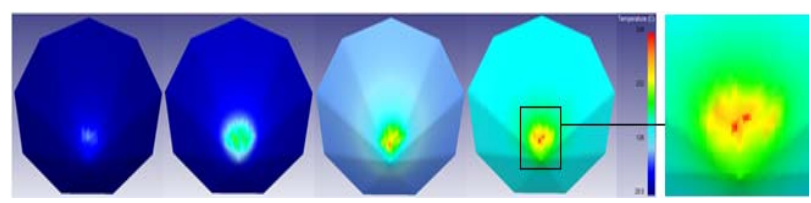

(b) The change process of grinding temperature for grain
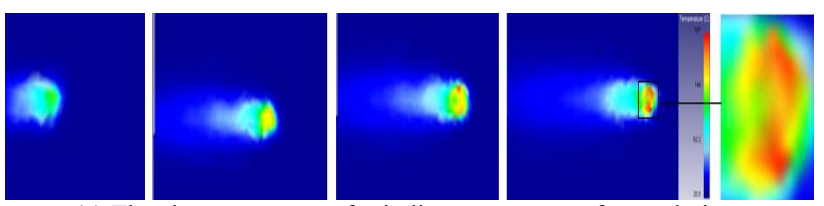

(c) The change process of grinding temperature for workpiece

Figure 6 . The change process of grinding temperature

The high temperature area of cone was most large (Refer in Fig.7), and increasing of the number of edges, the high temperature area increased. Because of increasing of the number of edges, $\theta$ increased. The contact area increased. Increasing of the number of edges, the highest temperature of grinding temperature was uptrend. Where, the cone was taken a pyramid of the edge number infinite (Refer in Fig.8).

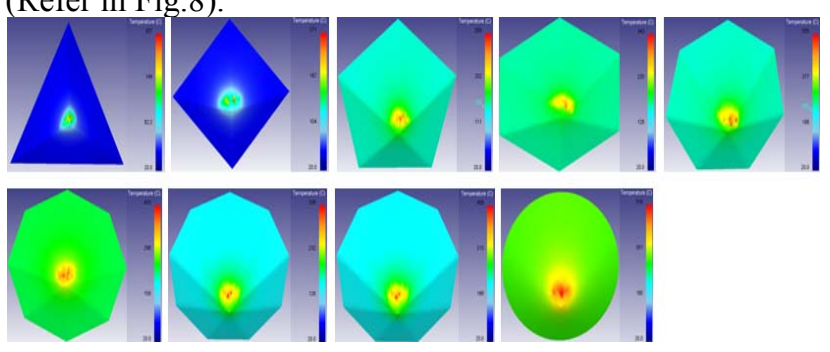

Figure 7. The grinding temperature distribution of different grain shape 


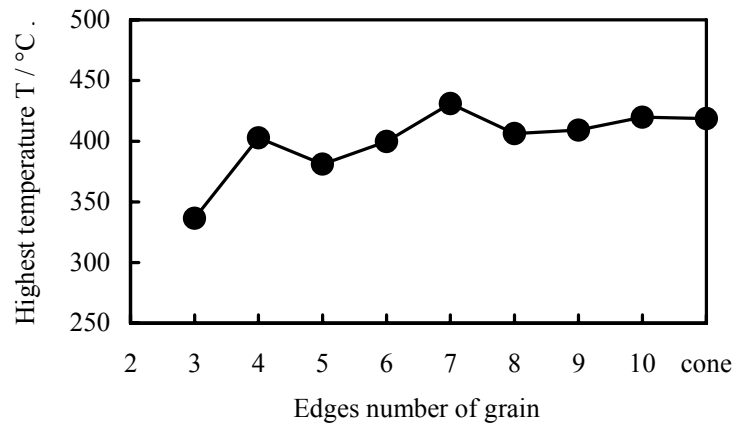

Figure 8 . The highest grinding temperature with the edges number of grain

\section{CONCLUSIONS}

Increasing of the number of edges, the resultant force $F$, normal grinding force $F_{z}$ and tangential grinding force $F_{y}$ were uptrend, the grinding force $F_{x}$ in feed direction was downtrend. The heat flux was less for triangular pyramid, rectangular pyramid, pentagonal pyramid and hexagonal pyramid. And the heat flux was high for others of grain shapes. The high temperature area of cone was most large, and increasing of the number of edges, the high temperature area increased. Increasing of the number of edges, the highest temperature of grinding temperature was uptrend.

\section{ACKNOWLEDGMENT}

This work was supported by the National Natural Science Foundation of China (No.51275083)

\section{REFERENCES}

[1] Su Chong, $\mathrm{Xu} \mathrm{Li,} \mathrm{Li} \mathrm{Minggao} \mathrm{and} \mathrm{Ma} \mathrm{Jijun.} \mathrm{Study} \mathrm{on} \mathrm{modeling} \mathrm{and}$ cutting simulation of abrasive grains. Acta Aeronatica et Astronautica Sinica, 33(11),pp. 2130-2135,2012.

[2] Fang, L., Cen, Q., Sun, K., Liu, W., Zhang, X., \& Huang, Z.. Fem computation of groove ridge and monte carlo simulation in two-body abrasive wear. Wear, 258, pp. 265-274,2005.

[3] Wang, W. S., Su, C., Pang, Z. R., and Hou, J. M.. Finite element simulation of chip formation with single grain. Key Engineering Materials, 416,pp.210-215, 2009.

[4] Chen J., Xu X. W., Yuan B. Y., Deng J. X., and Xing X.R.. Thermal expansion of cubic boron nitride. Acta Metallurfica Sinica,39,(9),pp.952-954,2003 